Tropical Journal of Pharmaceutical Research January 2016; 15 (1): 13-18

ISSN: $1596-5996$ (print); 1596-9827 (electronic)

(C) Pharmacotherapy Group, Faculty of Pharmacy, University of Benin, Benin City, 300001 Nigeria.

All rights reserved.

Available online at http://www.tjpr.org

Original Research Article

http://dx.doi.org/10.4314/tjpr.v15i1.2

\title{
Buccal Transmucosal Delivery System of Enalapril for Improved Cardiac Drug Delivery: Preparation and Characterization
}

\author{
Wen-Shuai He, Hao-Wei Xiong, Dan Xi, Tian-Tian Luo, Hao Lu, Meng-Hao Li, Ji- \\ Cheng Liu and Zhi-Gang Guo* \\ Division of Cardiology, Nanfang Hospital, Southern Medical University, Guangzhou 510515, China
}

*For correspondence: Email: guozhg51@gmail.com; Tel/Fax: 0086-20-61641508

Received: 13 March 2015

Revised accepted: 19 November 2015

\begin{abstract}
Purpose: To prepare and characterize buccal transmucosal delivery system of enalapril maleate for overcoming its low bioavailability, and hence provide improved therapeutic efficacy and patient compliance.

Methods: Transmucosal drug delivery systems of enalapril maleate were formulated as buccal films by solvent casting technique using polyvinylpyrrolidone K90, hydroxypropyl methylcellulose, sodium carboxymethylcellulose (high viscosity). The films were evaluated for film weight, thickness, folding endurance, drug content uniformity, surface $\mathrm{pH}$, in vitro residence time, in vitro drug release and ex-vivo permeation.

Results: All the formulations showed high drug content (96.45 to $98.49 \%)$. Those with good swelling showed good residence time. In vitro drug release was highest for films prepared with high viscosity grade sodium carboxymethylcellulose (SCMC- HV,F2), releasing $92.24 \%$ of drug in 1.5 h) followed by F4 (containing polyvinyl pyrrolidone $\mathrm{K}-901 \% \mathrm{w} / \mathrm{v}$ and SCMC (HV) $1 \% \mathrm{w} / \mathrm{v}$ ). Ex-vivo drug permeation at the end of $10 \mathrm{~h}$ was 82.24 and $89.9 \%$ for F2 and F4, respectively.

Conclusion: Prompt drug release was obtained from the formulation (F2) containing SCMC $2 \% \mathrm{w} / \mathrm{v}$ with $10 \mathrm{mg}$ enalapril. However, on the basis of the highest swelling and residence time, and controlled drug release, formulation F4 (containing PVP K-90 and SCMC HV) would be suitable for the development of buccal film for effective therapy of cardiac diseases.
\end{abstract}

Keywords: Cardiac disease, Transmucosal, Buccal films, Enalapril maleate, Drug release, Ex-vivo permeation

Tropical Journal of Pharmaceutical Research is indexed by Science Citation Index (SciSearch), Scopus, International Pharmaceutical Abstract, Chemical Abstracts, Embase, Index Copernicus, EBSCO, African Index Medicus, JournalSeek, Journal Citation Reports/Science Edition, Directory of Open Access Journals (DOAJ), African Journal Online, Bioline International, Open-J-Gate and Pharmacy Abstracts

\section{INTRODUCTION}

In recent years transmucosal drug delivery systems (TMDDSs) have been investigated for delivering the drugs across the various different mucosa (like oral, buccal, nasal, vaginal or rectal) for gaining various advantages across the conventional oral dosage forms. These advantages include providing prompt action, preventing the hepatic first pass metabolism, reducing the gastrointestinal irritation and reducing the dosage frequency [1,2]. The transmucosal delivery occurs when a drug delivery system is kept in intimate contact of a mucous membrane (buccal, vaginal, nasal, rectal etc.) for an extended period of time [3]. The bioadhesion occurs due to swelling of delivery system (due to imbibement of mucous) which 
follows the entanglement of polymer chains with that of mucin molecules. After the chain entanglement the drug diffuses across the mucosa $[1,3,4]$.

Among the various mucosae the buccal mucosa is best suited for local as well as systemic delivery of drugs. Its properties such as high vascularization, circumvention of the first pass metabolism and better patient compliance (than other mucosal sites) make it as an ideal route for transmucosal drug delivery [4-7]. Moreover, the improved bioavailability over the other sites available for TMDDS is the vital factor associated with transmucosal buccal drug delivery. These dosage forms are economic and patient friendly also.

The microenvironment of the mucosa governs the drug dissolution (release) and permeation through the mucosa; and the properly designed TMDDS can modulate it [8]. Mucoadhesive polymers are used for the formulation of TMDDS. These polymers generally are the polymers and their different grades with high molecular weight, high viscosity, greater flexibility and optimum chain length [9-13].

Transmucosal buccal delivery has been investigated for various drugs including protein and peptides [14-17]. Various TMDDS like tablets, films, patches, disks, strips, ointments and gels have been investigated [14-21]. Out of these transmucosal buccal films have been reported to be more flexible, comfortable with relatively longer residence time (than that of oral gels) on the mucosa. These films also show more protectant effect on the local wound surface for oral diseases [21-23].

Enalapril maleate is an angiotensin converting enzyme (ACE) inhibitor, used mainly in the treatment of hypertension and angina pectoris. It has low bioavailability $(40-60 \%)$ due to hepatic first pass metabolism [24-26]. Hence to improve its therapeutic efficacy and bioavailability, the drug may be administered by buccal route using buccal films. Buccal delivery of enalapril maleate may circumvent hepatic first pass metabolism to improve its bioavailability. Hence the present study aimed to formulate and characterize transmucosal buccal films of enalapril maleate with the use of mucoadhesive polymers, including sodium carboxymethylcellulose (SCMC), hydroxylpropyl methylcellulose (HPMC), hydroxyethylcellulose (HEC) and polyvinyl pyrrolidone K-90 (PVP K-90).

\section{EXPERIMENTAL}

Enalapril maleate, PVP K-90, HPMC (47 centipoise), SCMC (high viscosity grade) were obtained from Sigma Aldrich, US. Other chemicals used were of analytical grade. The films were prepared using solvent casting method.

\section{Preparation of transmucosal buccal films}

Buccal films of enalapril maleate were prepared by solvent casting technique using film forming mucoadhesive polymers based on the composition in Table 1.

Table1: Composition of transmucosal buccal films of enalapril maleate

\begin{tabular}{lcccccc}
\hline Ingredient & \multicolumn{6}{c}{ Formulation } \\
\cline { 2 - 7 } (\% w/v) & F1 & F2 & F3 & F4 & F5 & F6 \\
\hline Drug & 2 & 2 & 2 & 2 & 2 & 2 \\
PVP K-90 & 2 & - & - & 1 & 1 & - \\
HPMC K15 & - & - & 2 & - & 1 & 1 \\
SCMC (HV) & - & 2 & - & 1 & - & 1 \\
\hline
\end{tabular}

Abbreviations: PVP - polyvinylpyrrolidone, HPMC hydroxypropylmethylcellulose, SCMC (HV) - sodium carboxymethylcellulose (high viscosity grade)

HPMC was weighed $(100 \mathrm{mg})$ accurately and dissolved in minimum ethanol. After the swelling of polymer solution (standing time $10 \mathrm{~min}$ ) more $(5 \mathrm{ml})$ ethanol was added to the swelled polymer solution and the dispersion was kept for stirring (400 rpm, $15 \mathrm{~min}$ ). To this solution, propylene glycol was added. Ethanolic enalapril maleate solution was prepared and added to the polymer solution. The solution was vortexed and then stirred for $15 \mathrm{~min}$ at $400 \mathrm{rpm}$. The resulting solution was filled into vials, leaving little space over the surface and kept overnight. This step removed any air bubble in the drug-polymer solution. The bubble free drug polymer solution was poured into glass Petri dish placed over a flat surface with Inverted funnel placed over the dish (to avoid sudden evaporation). These Petri dish were kept for $12 \mathrm{~h}$ at room temperature for drying and solvent evaporation. The prepared dry films were removed, cut into size of $2 \mathrm{~cm}$ diameter, kept in butter paper and stored in a desiccator till further use.

\section{Determination of film weight, thickness and folding endurance}

Film weight (by digital balance, Fisher Brand PS200 ) and thickness (by micrometer screw gauge, Mitutoyo MMO-25DS) were determined $(n=3)$. Folding endurance was determined by 
repeatedly folding a small strip of size $(2 \times 2 \mathrm{~cm})$ of film at the same place till it broke (Table 2).

\section{Drug content uniformity measurement}

To determine the drug content uniformity, three film units of each formulation were taken in separate $100 \mathrm{ml}$ volumetric flasks, $100 \mathrm{ml}$ of methanol was added and continuously stirred for $4 \mathrm{~h}$ (till all the contents are dissolved). The solutions were filtered, diluted suitably and analyzed at $213 \mathrm{~nm}$ in a UV spectrophotometer (Lambda 25, Perkin Elmer, US). The mean value of drug content of three films was taken.

\section{Measurement of surface $\mathrm{pH}$}

Surface $\mathrm{pH}$ was determined by $\mathrm{pH}$ meter after keeping the hydrated films on agar plate for $1 \mathrm{~h}$ for swelling $[27,28]$.The swelling study was performed in $\mathrm{pH} 6.6$ phosphate buffer by a previously reported [28].

\section{Determination of in vitro residence time}

In vitro residence time was determined using USP disintegration apparatus using $\mathrm{pH} \quad 6.6$ phosphate buffer (PB) as the disintegration medium $\left(800 \mathrm{ml}, 37 \pm 2{ }^{\circ} \mathrm{C}\right)$. On the surface of a glass slab the segments of rat intestinal mucosa (each of $3 \mathrm{~cm}$ length) were glued and then the slab was vertically attached to the apparatus. Three films of each formulation were hydrated (on one surface using $\mathrm{pH} 6.6 \mathrm{~PB}$ ) and the hydrated surface was brought into contact with the mucosal membrane. The glass slab was vertically fixed to the apparatus and allowed to move up and down. The film was completely immersed in the buffer solution at the lowest point and was out at the highest point. The time required for complete erosion or detachment of the film from the mucosal surface was recorded $(n=3)$ as given in Table 2.

\section{Evaluation of in vitro drug release}

In vitro drug release study was performed in a USP XXIV 8-station dissolution apparatus, type 1, with $900 \mathrm{ml} \mathrm{pH} 6.6$ phosphate buffer (PB) as dissolution medium, maintained at $37 \pm 0.5{ }^{\circ} \mathrm{C}$ and $50 \mathrm{rpm}$ for $6 \mathrm{~h}$. One film of each formulation was fixed to the central shaft using an adhesive. At predetermined time samples were withdrawn from each station, filtered, diluted suitably and then analyzed spectrophotometrically at $213 \mathrm{~nm}$.

\section{Ex vivo permeation study}

Ex vivo permeation studies of mucoadhesive buccal films of enalapril through an excised layer of porcine buccal mucosa (washed with $\mathrm{pH} 7.4$ $\mathrm{PB}$ and trimmed to remove additional tissues before using) were carried out using the modified Franz diffusion cell[17,28-30]. A $2.0 \mathrm{~cm}$ diameter film of each formulation under study was placed in intimate contact with the excised porcine buccal mucosa and the topside was covered with aluminum foil as a backing membrane. The contents of receptor compartment filled with 100 $\mathrm{ml}$ of $\mathrm{pH} 7.4$ phosphate bufferwere stirred on a magnetic stirrer at $37 \pm 10$. The samples were withdrawn at predetermine time (replaced with same volume of fresh media), filtered, diluted suitably and then analyzed using UV spectrophotometer at $213 \mathrm{~nm}$.

\section{Statistical analysis}

The results are expressed as mean \pm standard deviation (SD). Statistical analysiswas carried out by analysis of variance (ANOVA) using SPSS software (IBM SPSS Statistics 2015). $P<0.05$ was considered statistically significant.

\section{RESULTS}

\section{Film weight, thickness and folding endurance}

The films showed uniform thickness throughout. The film thickness was found to be from $0.140 \pm$ 0.017 to $0.220 \pm 0.034 \mathrm{~mm}$ (Table 2).

The weights of different formulation were found to be in the range of $56 \pm 1.02 \mathrm{mg}$ to $94 \pm 0.82$ mg. Folding endurance was measured manually by folding the film repeatedly at a point till they broke. Films did not show any cracks even after folding for more than 197 times. The folding endurance was found to be in the range of $197.02 \pm 14.45$ to $354.42 \pm 15.50$.

\section{Drug content}

The percent drug content was found to be in the range of $96.45 \pm 1.10$ to $98.49 \pm 1.25 \%$ (Table 2).

\section{Surface $\mathrm{pH}$}

The surface $\mathrm{pH}$ of all formulations was within \pm 0.5 units of the neutral $\mathrm{pH}$ (6.4 to 6.8) and hence no mucosal irritation were expected and ultimately achieve patient compliance.

\section{Swelling}

Swelling of the films in phosphate buffer solution (PBS, pH 6.6) 
Table 2: Physical characterization of transmucosal buccal films of enalapril maleate

\begin{tabular}{ccccccc}
\hline $\begin{array}{l}\text { Formulation } \\
\text { code }\end{array}$ & $\begin{array}{c}\text { Thickness } \\
(\mathbf{m m})\end{array}$ & $\begin{array}{c}\text { Folding } \\
\text { endurance }\end{array}$ & $\begin{array}{c}\text { Content } \\
\text { uniformity (\%) }\end{array}$ & $\begin{array}{c}\text { Surface } \\
\mathbf{p H}\end{array}$ & $\begin{array}{c}\text { Swelling } \\
\text { index (2h) }\end{array}$ & $\begin{array}{c}\text { In vitro } \\
\text { residence } \\
\text { time (h) }\end{array}$ \\
\hline F1 & 0.168 & 354.42 & 96.98 & 6.40 & $19.94 \pm 1.02$ & 1.50 \\
& \pm 0.102 & \pm 15.50 & \pm 1.02 & \pm 0.019 & & \pm 0.50 \\
F2 & 0.140 & 292.00 & 97.90 & 6.80 & 27.65 & 2.25 \\
& \pm 0.017 & \pm 18.09 & \pm 1.45 & \pm 0.002 & \pm 2.02 & \pm 0.28 \\
F3 & 0.201 & 282.50 & 96.08 & 6.62 & 29.40 & 2.75 \\
& \pm 0.024 & \pm 12.63 & \pm 1.24 & \pm 0.038 & \pm 1.12 & \pm 0.62 \\
F4 & 0.168 & 217.82 & 98.42 & 6.45 & 48.11 & $4.00 \pm 0.90$ \\
& \pm 0.120 & \pm 12.30 & \pm 1.06 & \pm 0.026 & \pm 1.09 & 3.50 \\
F5 & 0.220 & 197.02 & 98.49 & 6.56 & 34.92 & \pm 0.60 \\
& \pm 0.034 & \pm 14.45 & \pm 1.25 & \pm 0.014 & \pm 1.04 & 3.75 \\
F6 & 0.180 & 259.08 & 96.45 & 6.49 & 47.90 & \pm 0.50 \\
\hline
\end{tabular}

Data are expressed as mean $\pm S D(n=3)$

was more pronounced in film F4 $(48.11 \pm 1.09)$ followed by $\mathrm{F} 6(47.90 \pm 1.29)$ which contained PVP- SCMC and HPMC-SCMC, respectively (Table 2).

\section{In vitro residence time}

The in vitro residence time of various formulations was in the rank order of F4 > F6> $\mathrm{F} 5>\mathrm{F} 3>\mathrm{F} 2>\mathrm{F} 1$. The in vitro residence time of the films were found to be in good tune with swelling and drug release properties.

\section{In vitro drug release}

In vitro release studies of various formulations were performed in PBS as dissolution medium. Significant difference in drug release was found for the various transmucosal buccal films of enalapril maleate (Fig 1).

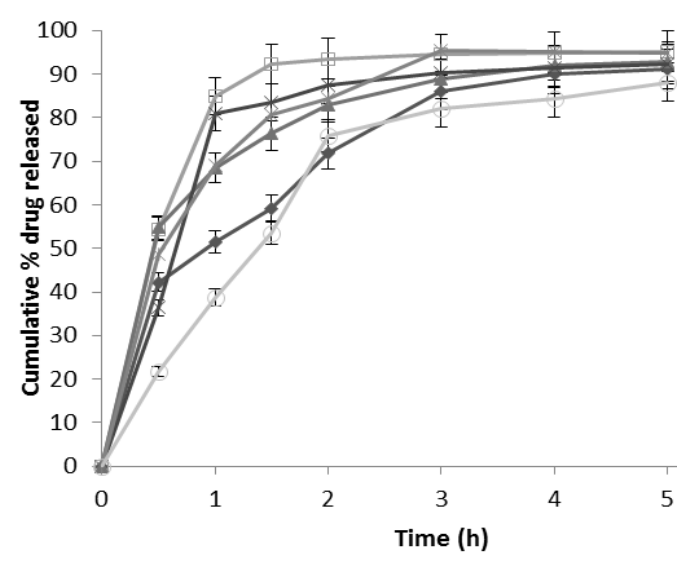

Fig 1: In vitro drug release study: Cumulative percent drug release of transmucosal buccal films in $\mathrm{pH} 6.6$ phosphate buffer for formulation F1 (-४); F2 (-口-); F3 (-A -); F4 (-x-); F5(-*) and F6Q-)
SCMC (HV) containing film (F2) showed highest drug release (with rapid release of drug, $92.24 \%$ in $1.5 \mathrm{~h}$ ). After the formulation F2, the formulation F4 (containing PVP K-90 $1 \% \mathrm{w} / \mathrm{v}$ and SCMC (HV) $1 \% \mathrm{w} / \mathrm{v}$ ) showed the better drug release.

\section{Ex-vivo drug release}

For ex-vivo drug release study the formulation F2 (containing SCMC $2 \% \mathrm{w} / \mathrm{v}$ ) and $\mathrm{F} 4$ (containing PVP K-90 $1 \% \mathrm{w} / \mathrm{v}$ and SCMC HV $1 \% \mathrm{w} / \mathrm{v}$ ) were selected. The formulation F2 was selected due to highest and fastest in vitro drug release while F4 was selected due to highest swelling, longest residence time and rapid (83.48 \% in $1.5 \mathrm{~h}$ ) as well as higher in vitro drug release $(92.24 \%$ at the end of $5 \mathrm{~h}$ ). In ex vivo study, drug permeation through the porcine buccal mucosa was determined for formulation F2 and F4 (Fig 2).

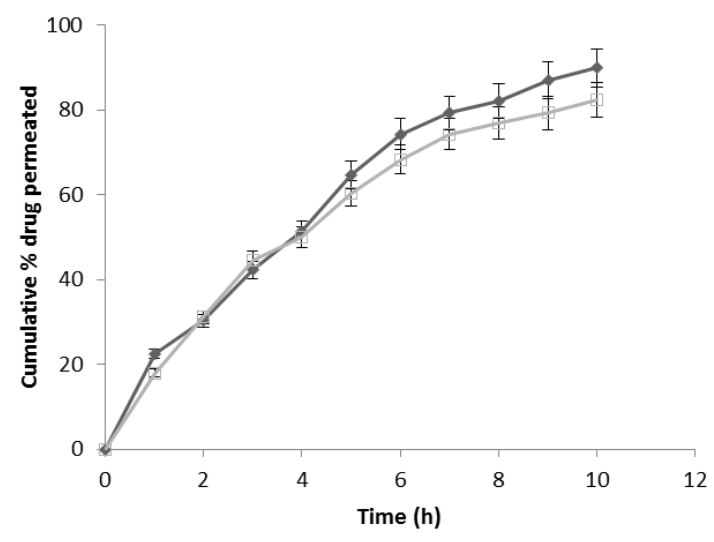

Fig 2: Ex-vivo permeation studies of selected transmucosal buccal films of enalapril maleate; Permeation studies in $\mathrm{pH} 7.4$ phosphate buffer of formulations F2 (-口-) containing SCMC $2 \% \mathrm{w} / \mathrm{v}$, and F4 (- $\boldsymbol{\Delta}$-) containing PVP K-90 $1 \% \mathrm{w} / \mathrm{v}$ and SCMC $1 \%$ $\mathrm{w} / \mathrm{v}$ with $10 \mathrm{mg}$ enalapril in each film of $2 \mathrm{~cm}$ diameter 
The ex-vivo drug permeation at the end of $10 \mathrm{~h}$ was $82.24 \%$ and $89.9 \%$ for F2 and F4, respectively. The correlation coefficient values were 0.9274 and 0.945 for $\mathrm{F} 2$ and $\mathrm{F} 4$, respectively showing good correlation. It was concluded that the release kinetics followed zero order. As the Higuchi plots of F2 and F4 showed linearity (with correlation coefficient values of 0.910 and 0.958 for $\mathrm{F} 2$ and F4, respectively) the drug permeation was confirmed to be through the matrix diffusion process.

\section{DISCUSSION}

In cardiac diseases, prompt delivery of the drug is important especially in emergency situations. Moreover, when a patient is in capable of swallowing medicaments orally the alternative routes with improved bioavailability such as buccal route have been found to be very promising.

The physical properties of buccal films like thickness weight, folding endurance values were found to be optimum to reveal good film properties. The higher drug loading values of the films indicated the uniform dispersion of drug in the prepared films which makes the loading and delivery of therapeutic dosage of the drug.

The acidic or alkaline $\mathrm{pH}$ may be a potential irritant to the buccal mucosa with adverse effect on the drug release and degree of hydration of polymers. Therefore the surface $\mathrm{pH}$ of buccal film was determined to optimize both drug release and mucoadhesion. The $\mathrm{pH}$ of films being in good tune with the $\mathrm{pH}$ of buccal mucosa would not be expected to cause irritation and to affect adversely the drug release or hydration of polymers. The greater swelling property of SCMC (HV) was found to play a key role.

The enhanced erosion rate associated with the non-ionic polymers (HPMC and SCMC) in the present study is well supported by the various previous studies $[28,31,32]$. The mucous and the biological fluid ( $\mathrm{pH}$ 6.6) of buccal region gets imbibed into the transmucosal delivery system and this induction of swelling of particles in the matrix (of drug-polymer) make the transmucosal device a highly porous swollen matrix. The drug starts diffusing out of the highly porous matrix with simultaneous erosion of the polymer matrix. So the swelling property is closely associated with the residence time of buccal transmucosal film.

In in vitro drug release studies, formulation F2 showed rapid and the best release due to easy erosion of the polymer matrix which could not hold the drug for longer period of time as compared to other formulations. However, the formulation can be acceptable for the prompt delivery of the drug in cardiac emergencies.

On the basis of the properties of high swelling, long residence time, high and fast in vitro drug release, formulations $\mathrm{F} 2$ and $\mathrm{F} 4$ were selected for ex vivo studies across the porcine buccal mucosa. Due to the low permeability of mucosa and unidirectional flow of drug flux (due to presence of backing membrane in ex vivo study) the drug permeation was slower and lower as compared to the in vitro drug release. The zero order of drug release with matrix diffusion process as shown by the formulations in the ex vivo studies, was best suited for getting the better cardiac effects of enalapril through the transmucosal buccal films.

\section{CONCLUSION}

All the formulations showed good physicochemical properties including drug loading, swelling and in vitro residence properties and can be used for buccal transmucosal drug delivery of enalapril for delivery to systemic circulation for prompt or prolonged action depending on the polymers employed in developing the buccal films. However, in vivo, preclinical and clinical investigations need to be carried out before the findings can be translated to clinical settings.

\section{ACKNOWLEDGEMENT}

The authors acknowledge research grants from Natural Science Foundation of China (no. 81370380), Natural Science Foundation of Guangdong Province of China (no. S2013010014739) and Science and Technology Foundation of Guangdong Province of China (no. 2012B091100155).

\section{REFERENCES}

1. Hombach J, Bernkop-Schnürch A. Mucoadhesive drug delivery systems. HandbExpPharmacol. 2010; (197): 251-266.

2. Shaikh $R$, Singh TRR, Garland MJ, Woolfson AD, Donnelly RF. Mucoadhesive drug delivery systems $J$ Pharm Bioallied Sci. 2011; 3(1): 89-100.

3. Smart JD. The basics and underlying mechanisms of mucoadhesion. Adv Drug Deliv Rev 2005; 57: 15561568.

4. Bruschi ML, de Freitas O. Oral bioadhesive drug delivery systems. Drug Dev Ind Pharm. 2005; 31(3): 293-310. 
5. Pathan SA, lqbal Z, Sahani JK, Talegaonkar S, Khar RK, Ahmad FJ. Buccoadhesive drug delivery systems-extensive review on recent patents. Recent Pat Drug DelivFormul. 2008; 2(2): 177-188.

6. Campisi G, Paderni C, Saccone R, Di Fede O, Wolff A, Giannola LI. Human buccal mucosa as an innovative site of drug delivery. Curr Pharm Des. 2010; 16(6): 641652.

7. Smart JD. Buccal drug delivery. Expert Opin Drug Deliv. 2005; 2(3): 507-517.

8. Sudhakar $Y$, Kuotsa K, Bandyopadhyay AK. Buccal bioadhesive drug delivery - A promising option for orally less efficient drugs. J Control Release 2006; 114: 15-40.

9. Patel VF, Liu F, Brown MB. Advances in oral transmucosal drug delivery. J Control Release. 2011; 153(2): 106-116.

10. Jasti $B, L i X$, Cleary $G$. Recent advances in mucoadhesive drug delivery systems. Pharmatech 2003: 194-196.

11. Salamat-Miller N, Chittchang1 M, Johnston TP. The use of mucoadhesive polymers in buccal drug delivery. Adv Drug Deliv Rev 2005; 57: 1666-1691

12. Shojaei AH: Buccal mucosa as a route for systemic drug delivery: a review. J. Pharm. Pharm Sci1998; 1:15- 30

13. Bagan J, Paderni C, Termine N, Campisi G, Lo Russo L, Compilato D, Di Fede O. Mucoadhesive polymers for oral transmucosal drug delivery: a review. Curr Pharm Des. 2012; 18(34): 5497-5514.

14. Senel S, Kremer M, Nagy K, Squier C. Delivery of bioactive peptides and proteins across oral (buccal) mucosa. Curr Pharm Biotechnol. 2001; 2(2): 175-186.

15. Pather SI, Rathbone MJ, Senel S. Current status and the future of buccal drug delivery systems. Expert Opin Drug Deliv. 2008; 5(5): 531-542.

16. Veuillez $F$, Kalia $Y N$, Jacques $Y$, Deshusses J, Buri $P$. Factors and strategies for improving buccal absorption of peptides. Eur J Pharm Biopharm. 2001; 51(2): 93109.

17. Morales JO, McConville JT. Manufacture and characterization of mucoadhesive buccal films. Eur $J$ Pharm Biopharm. 2011; 77(2): 187-199.

18. Perioli L, Ambrogi V, Rubini D, et al. Novel mucoadhesive buccal formulation containing metronidazole for the treatment of periodontal disease. J Control Release 2004; 95: 521-533.

19. Shin SC, Bum JP, Choi JS. Enhanced bioavailability by buccal administration of triamcinolone acetonide from the bioadhesive gels in rabbits. Int $J$ Pharm 2009; 209: 37-43.

20. Gilhotra RM, Ikram M, Srivastava S, Gilhotra N. A clinical perspective on mucoadhesive buccal drug delivery systems. J Biomed Res. 2014; 28(2): 81-97.

21. Preis $M$, Woertz C, Kleinebudde $P$, Breitkreutz J. Oromucosal film preparations: classification and characterization methods. Expert Opin Drug Deliv. 2013; 10(9): 1303-1317.

22. Nafee NA, Ismail FA, Boraie NA, Mortada LM. Mucoadhesive buccal patches of miconazole nitrate: in vitro/in vivo performance and effect of ageing. Int $J$ Pharm 2003; 264: 1-14.

23. Şenel S, Rathbone MJ, Cansız M, Pather I. Recent developments in buccal and sublingual delivery systems. Expert Opin Drug Deliv. 2012; 9(6):615-628.

24. Zhou XH, Li Wan Po A. Stability and in vitro absorption of captopril, enalapril and lisinopril across the rat intestine. BiochemPharmacol. 1994; 47(7): 1121-1126.

25. Svanström $H$, Pasternak B, Melbye M, Hviid A. Use of different types of angiotensin converting enzyme inhibitors and mortality in systolic heart failure. Int $\mathrm{J}$ Cardiol. 2014; 182C: 90-96.

26. Raia JJ Jr1, Barone JA, Byerly WG, Lacy CR. Angiotensin-converting enzyme inhibitors: a comparative review. DICP. 1990; 24(5): 506-525.

27. Semalty $M$, Semalty $A$, Kumar G. Formulation and characterization of mucoadhesive buccal films of glipizide. Indian J Pharm Sci 2008; 70: 43-48.

28. Semalty A, Bhojwani M, Bhatt GK. Design and evaluation of mucoadhesive buccal films of diltiazem hydrochloride. Indian J Pharm Sci2005; 67(5): 548-552.

29. Junginger HE, Hoogstraate JA, Verhoef JC, Recent advances in buccal drug delivery and absorption: in vitro and in vivo studies. J Control Release 1999; 62: 149159.

30. Davidovich-Pinhas M, Bianco-Peled H. Mucoadhesion: a review of characterization techniques. Expert Opin Drug Deliv. 2010; 7(2): 259-271.

31. Samuelov $Y$, Donbrow M, Friedman M. Sustained release of drugs from ethyl cellulose-polyethylene glycol films and kinetics of drug release. J Pharm Sci 1979; 68; 325-329.

32. El-Khodairy KA, Effect of physicochemical properties of the hydrophilic Gantrez matrix. Alex J Pharm Sci 2001; 15: 35-40. 